\title{
Ageing as an Important Risk Factor for Cancer
}

\author{
KAREL SMETANA JR..$^{1,2}$, LUKÁŠ LACINA ${ }^{1,3}$, PAVOL SZABO ${ }^{1,2,4}$, \\ BARBORA DVOŘÁNKOVÁ ${ }^{1,2}$, PROKOP BROŽ ${ }^{5}$ and ALEKSI ŠEDO ${ }^{6}$ \\ ${ }^{1}$ Institute of Anatomy, ${ }^{3}$ Department of Dermatology and Venerology, and \\ ${ }^{6}$ Institute of Biochemistry and Experimental Oncology, First Faculty of Medicine, \\ Charles University, Prague, Czech Republic; \\ ${ }^{2}$ BIOCEV, Vestec, Czech Republic; \\ ${ }^{4}$ Department for Biomedical Research, East-Slovak Institute of Cardiovascular Diseases, \\ Inc., Kosice, Slovak Republic; \\ ${ }^{5}$ Catholic Theological Faculty, Charles University, Prague, Czech Republic
}

\begin{abstract}
An ageing population is a typical feature of many developed countries across the world. Analyzed from a biomedical and philosophical point of view, this phenomenon is also a potential risk factor for social sustainability of communities. The association between ageing and cancer seems to be more than apparent. Therefore, the further increase of epidemic-like incidence of malignant tumors in a population can be expected in the near future. Elderly people usually suffer from age-dependent diseases, and such polymorbidity can seriously affect the treatment of malignant tumors. Such an impending situation may be associated with multiple medical, social and economic issues. This article summarizes data about the possible molecular mechanism influencing rapid spreading of tumors in the elderly population. Reduction of the activity of DNA repair machinery is a likely genetic cause. Besides this, even epigenetic mechanisms can influence this process. In this context, the role of cancer stroma in controlling multiple biological properties of tumors is a prospective target for translational research with potential therapeutic outcomes.
\end{abstract}

This article is freely accessible online.

Correspondence to: Karel Smetana, Institute of Anatomy, First Faculty of Medicine, Charles University, U. Nemocnice 3, 128 00, Prague 2, Czech Republic. Tel.: +42 0224965873, Fax: +42 0224965770, e-mail: karel.smetana@lf1.cuni.cz and Aleksi Šedo, Institute of Biochemistry and Experimental Oncology, First Faculty of Medicine, Charles University, U Nemocnice 5, 12853, Czech Republic. Tel.: +42 0224965735, Fax: +42 0224915413, e-mail: aleksi@cesnet.cz

Key Words: Ageing, cancer incidence, DNA repair, genetic instability, cancer microenvironment, review.

\section{Cancer Incidence Is Increasing Worldwide}

The headlines of many articles inform us about epidemic incidence of cancer worldwide. It is disputable whether this reflects the truth or how much it reflects journalists' efforts to attract reader's attention to sensational information and thus improve the economical profit of their particular publication.

The epidemiologic data from the Czech Republic (and similarly from others) do indicate a remarkably high incidence of tumors $(1,2)$. According to the Czech Oncological Society (http://www.linkos.cz/en), almost 500,000 people suffer from cancer. About 80,000 new patients are diagnosed with cancer and 27,000 die from their disease each year. The majority of tumors were diagnosed in persons older than 55 years of age (3). This figure is alarming in the context of a country with population a little over 10 million citizens. There are many hypothetical explanations for this discouraging situation. One reason may be seen in the lifestyle, with a high caloric diet, stress, reduction of physical activity, exposure to pollution, frequently with a genotoxic effect. The progress in diagnostic technologies enabling effective screening of cancer and health authoritypromoted campaigns may also be behind this high increase of incidence, because these diseases can now be diagnosed in very early stages. Such new screening strategies also improve the results of therapy, which is more effective and also completely curative at the early stages of cancer. Comparison of the demographic situation from other countries also suggests a relationship between ageing and cancer incidence.

\section{An Ageing Population Influences Cancer Incidence}

It is first necessary to determine the factors that facilitate an increase of life expectancy in many countries. Consequently, 
Table I. Examples of life expectancy and cancer death rate, worldwide.

Country

Life expectancy (years)

Japan, Switzerland, San Marino, Italy, Singapore, Iceland, Andorra, Australia, Spain, Qatar ${ }^{+}$, Israel, Monaco, France,

Sweden, Canada, Luxembourg, Cyprus, Norway, New Zealand, Netherlands, Austria, Greece, Ireland, South Korea,

Finland, Germany, United Kingdom, Belgium, Malta, Slovenia, Portugal

Kuwait ${ }^{+}$, Denmark, Chile, Costa Rica, Bahrain ${ }^{+}$, United States, Cuba, Czech Republic, Barbados, Colombia ${ }^{+}$, Brunei $^{+}$,

Croatia, Cook Islands, Panama ${ }^{+}$, Peru, Maldives ${ }^{+}$, Uruguay, Estonia, Poland, Slovakia, Bosnia/Herzegovina, Ecuador,

Argentina, United Arab Emirates ${ }^{+}$, Turkey, Tunisia ${ }^{+}$, China, Venezuela ${ }^{+}$, Saudi Arabia ${ }^{+}$, Macedonia, Vietnam, Syria,

Bahamas, Hungary, Saint Lucia $^{0}$, Mexico ${ }^{+}$

Kenya, Marshall Islands ${ }^{0}$, Afghanistan, Rwanda, Tanzania ${ }^{+}$, Liberia ${ }^{+}$, Mauritania $^{+}$, Gambia $^{+}$, South Africa, Djibouti ${ }^{0}$,

Congo $^{+}$, Malawi $^{+}$, Benin $^{+}$, Togo $^{+}$, Ivory Coast ${ }^{+}$, Niger $^{+}$, Uganda, Burkina Fasso $^{+}$, Guinea $^{+}$, Zambia $^{+}, Z_{\text {Zimbabwe }}$

Equatorial Guinea ${ }^{+}$, Nigeria $^{+}$, Burundi, Cameroon $^{+}$, Mozambique $^{+}$, Chad $_{+}$, Angola $^{+}$, Mali $^{+}$, Swaziland $^{+}$, Lesotho $^{+}$,

Guinea-Bissau ${ }^{+}$,Somalia, D.R. Congo ${ }^{+}$, Central Africa ${ }^{+}$, Sierra Leone ${ }^{+}$

European countries, African countries. Death rate from cancer per 100,000 persons: ${ }^{+}<100,{ }^{0}$ data not available from World Life Expectancy (http://www.worldlifeexpectancy.com).

the links between ageing and its relationship to cancer will become more apparent. Life expectancy is progressively increasing worldwide, dramatically so in the course of the 20th century. The average human lifespan at the beginning of the 20th century was approximately 50-60 years of age and did not change until the beginning of the 1950s. Life expectancy increased in the following decades dramatically and has now reach around 80 years of age in many developed countries (4). The burden of mortality due to infectious diseases, which were the main cause of death until the middle of the 20th century, was significantly reduced after the massive introduction of sulfonamides and antibiotics to clinical practice. Cardiovascular diseases are still in the leading cause of death in many countries; however, associated mortality exhibits a decreasing tendency. Many patients survive longer due to the application of new therapeutic approaches (e.g. preventive cardiology) and novel procedures of interventional cardiology (5). This development has opened the way for expansion of malignant diseases in the elderly. Concerning the role of ageing, it is evident from Table I, that life expectancy over 75 years of age is very common in Europe, the Americas and in developed Asian countries. This life expectancy can reflect multiple aspects of human life, from lifestyle to climate. Above all, it also well reflects the wealth of a community. This latter aspect is primarily responsible for ease of the accessibility to medical care, including advanced medical technologies and modern therapeutics. Such communities or countries are also typically bearing the burden of high tumor incidence and associated mortality (http://www.worldlifeexpectancy.com). On the other hand, the lowest life span is seen in certain African countries. Despite the sparse population-based health data from these countries, the tumor incidence expressed as the death rate from cancer is significantly lower in comparison to countries with a high lifespan (6-8). Moreover, cancer-related mortality can be influenced by other factors such as the high percentage of human immunodeficiency virus (HIV) positivity and acquired immunodeficiency syndrome (AIDS)-associated cancer. This situation can be further exemplified by colorectal cancer; where its incidence is higher in Southern Africa with a higher life expectancy than in other countries of this region (9). These type of data evoke many questions which can help in understanding the mechanisms influencing the increased cancer incidence in the elderly.

\section{Biological Background of Ageing and Impact on Cancer Formation}

Ageing is an integral aspect of the life of all organisms, including humans. It is not easy to define all the processes limiting our lifespan. The explanation of ageing is, usually, abstract. For example, according to the Encyclopaedia Britannica, ageing is defined as a number of progressive physiological changes in an organism that lead to senescence, or a decline of biological functions and of the organism's ability to adapt to metabolic stress (http://www.britannica.com/ science/aging-life-process). Ageing itself is not a disease (10). It is the normal development of an individual (11). However, old age is associated with well-known, typical problems and related comorbidities (Table II) (12). On the cellular level, the ageing is associated with genomic instability, telomere attrition, epigenetic alterations, qualitative and quantitative changes of protein spectra, deregulated nutrient sensing, mitochondrial dysfunction, cellular senescence, stem cell exhaustion and altered intercellular communications $(13,14)$. These events result in the accumulation of irreparable damage to important processes in the body (15).

The age-altered stem cell can be a source of tissue/organ function failure or even cancer formation. It seems that the risk of developing cancer reflects the number of mitotic 
Table II. Problems typical of ageing.

\begin{tabular}{lc}
\hline System & Problem \\
\hline Nervous & Neurodegeneration \\
& Dementia \\
& Cognitive decline \\
Sensual & Eye disease (presbyopia, cataract, \\
& macular degeneration) \\
Cardiovascular & Hearing loss \\
& Atherosclerosis \\
Locomotory & Heart disease \\
& Sarcopenia \\
Metabolism & Osteoarthritis \\
\hline
\end{tabular}

divisions of adult tissue stem cells (16). This hypothesis highlights the role of ageing on the increased cancer incidence in population because the number of stem cell divisions must clearly be higher in the elderly in comparison to the young. This idea also underscores the proposed role of cancer stem cells in tumor formation and spreading (17). It is now well understood that precise DNA repair is critical in stem cells (14), making them more resistant to DNA damage (18). On the other hand, adult tissue stem cells face genotoxic stimuli over decades. Once their DNA-repair capacity is exhausted and attenuated, the resulting genetic instability in stem cells can be causally associated with cancer formation in the elderly (14). The process of ageing can be well described in cells with damaged DNA-repair activity (19) (Figure 1). Longevity seems to be associated with higher capacity for gene repair, as is apparent in the comparison of short- and long-living organisms (20). However, aging is associated with a reduction of gene repair. This can be well demonstrated in the case of DNA polymerase $\delta 1$, which is very important for DNA replication and repair. Expression of this enzyme is significantly reduced during the course of ageing of an individual. It is three times lower in lymphocytes from donors aged 70 years in comparison to a 30 year-old person (21). Similarly, human dermal fibroblasts (HDFs) isolated from donors of different ages significantly differ in gene expression activity (22). HDFs from elderly donors exhibit lower production of extracellular matrix. This is well correlated to clinical signs of skin ageing. HDF transition to myofibroblast after cytokine stimulation is also lower than in the case of cells collected from young donors. This can be also correlated to well-documented clinical differences in wound healing. Similarly, the number of DNA strand breaks and time required for their repair is significantly influenced by ageing $(22,23)$. Double-strand DNA breaks can even participate to

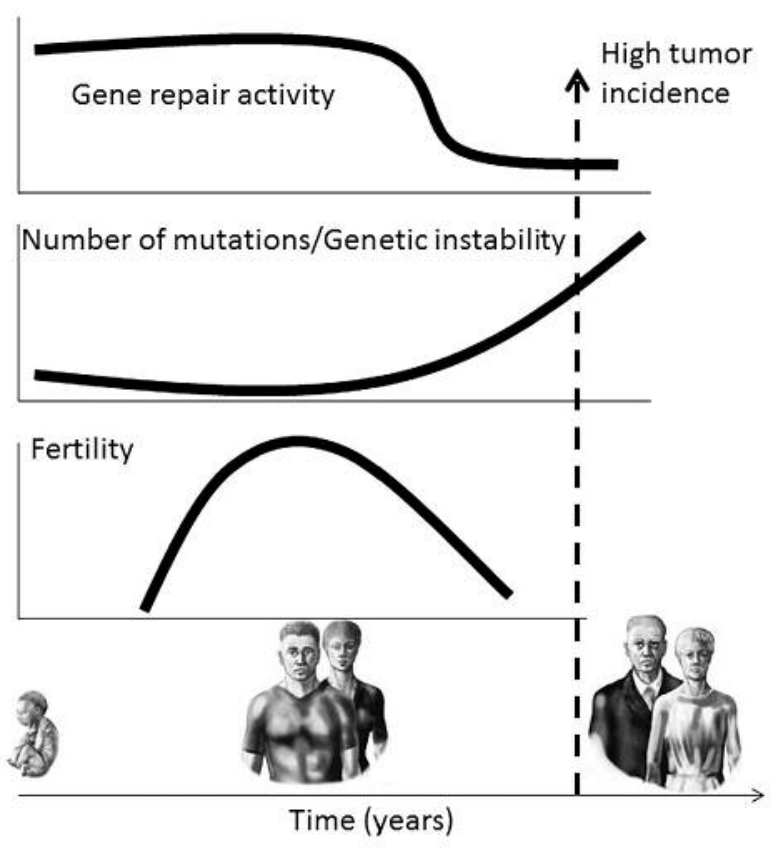

Figure 1. Schematic presentation of temporal coincidence between reduction of capacity for DNA repair, increased number of mutations increasing genetic instability, fertile age and beginning of the period of high incidence of malignant tumors in humans.

the loss of heterozygosity in the elderly and can be important for cancerogenesis $(24,25)$. The total number of mutations acquired during ageing is extremely high, and robust genomic technologies demonstrated that 3,000-13,000 genes per genome can be affected by 5,000-50,000 mutations (26). It is likely that such genomic alterations could be responsible for many health problems associated with ageing, such as neurodegeneration including Parkinson's and Alzheimer's disease $(27,28)$. The comparison of reduced DNA-repair activity, accumulation of mutations, cancer incidence and fertility seems to be interesting from a biological point of view (Figure 1). Accumulation of these alterations in tissue stem cells or cells forming their microenvironment can participate in the selection of aberrant clones that can give a rise to a malignant tumor $(29,30)$ (Figure 2). Genetically damaged stem cells as a potential cancer-initiating population are normally removed from the niche as demonstrated for example in hair graying, explained by the elimination of damaged melanocyte precursors (31). However, if this process of elimination is not successful, genetically unstable stem cells persist in their stem cell niche and their role in cancer initiation is highly probable (Figure 3 ). These genetic alterations can also significantly participate in the occurrence of cancer-related symptoms and comorbidities (Figure 3). 


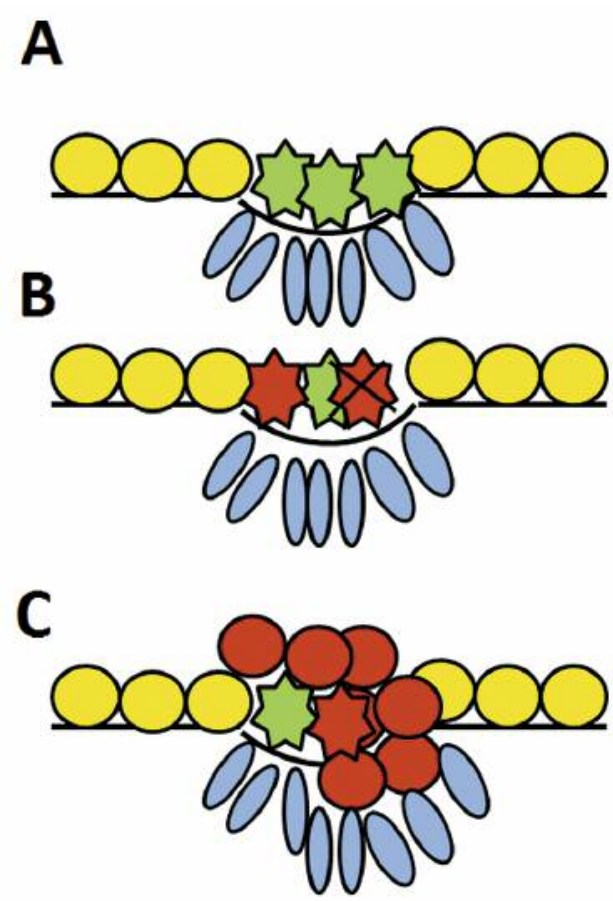

Figure 2. Model of the role of genetically altered stem cells in cancer formation. A: Normal tissue stem cells (green asterisks) located in their niche are supported by other cells, for example fibroblasts (blue oval cells). These tissue stem cells produce normal differentiated cells (yellow rings). B: When the stem cells are genetically altered (red asterisks), internal control mechanisms including immune surveillance try to remove them (crossed red asterisk) in order to prevent cancer formation. C: If their removal is not successful, these cells are cancer stem/initiating cells, the source of cancer origin and growth (red asterisk and rings). The cells originally supporting the stem cells will stimulate the growth and spread of the tumor.

Various cancer-specific genetic mutation signatures have been proposed. It is interesting in the context of this article that almost $75 \%$ of them are also seen in ageing $(32,33)$. This can be further well illustrated in clinical hematology, where a number of mutations of genes associated with leukemia was significantly elevated in $20 \%$ of healthy people aged over 90 years (34).

Summarizing the demographic, epidemiological and biological data, the life-time risk of developing cancer in Western societies is $50 \%$ (35).

\section{Mutations and Epigenetics}

During a lifetime, the human body encounters many exogenous stimuli resulting in mutagenic events. These can be due to physical factors (UV irradiation, X-ray etc.), or chemical substances (many food additives, air/water pollutants etc.). Regardless of their nature, they are

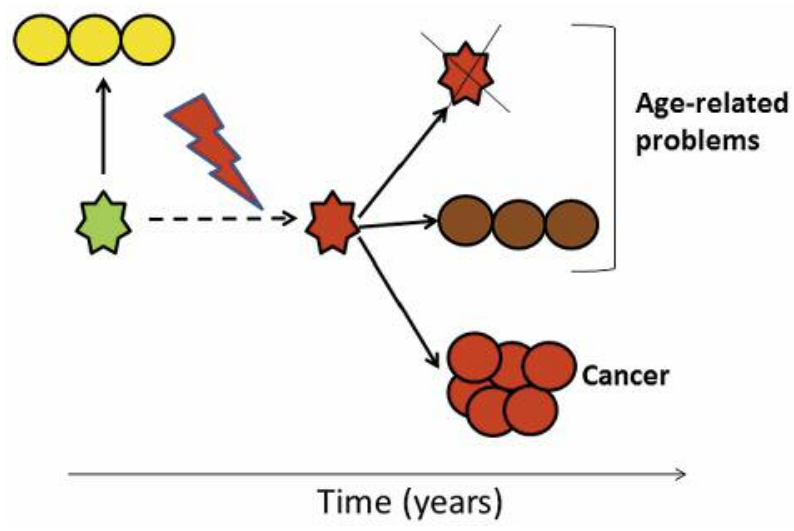

Figure 3. Model of the role of a genetically affected stem cell in the formation of age-associated symptoms and cancer. Normal tissue stem cells (green asterisk) produce normal functionally active cells (yellow rings). When these stem cells are genetically unstable due to accumulation of mutations (red asterisk), they are removed (crossed red asterisk), they produce functionally abnormal but non-tumor cells (brown circles) or cancer cells (red circles). A lack of cells arising from age-dependent removal of stem cells and the production of functionally abnormal differentiated cells can be responsible for ageing-associated problems.

associated with a genotoxic effect. Besides these exogenous mutagens, free radicals, such as highly potent superoxides, are produced by our own body as a by-product of metabolism. These reactive oxygen species can be considered as the main endogenous source of mutations. Once DNA errors are not repaired with a high accuracy and efficiency, they can be responsible for development of many major problems, including cancer. However, a certain frequency of errors occurring during DNA maintenance and replication in the cell cycle is naturally anticipated. Complicated cellular enzymatic machinery is, therefore, employed in their correction.

There are also longstanding discussions about effect of small doses of e.g. radiation. The linear no-threshold model is a model formerly used in radiation protection. Firstly, it was used to quantify radiation exposure and based on this theory, regulatory limits of radiation were set. It assumes that the long-term, biological damage is directly proportional to the total obtained dose. On the other hand, some others highlight that a certain threshold must be overcome before the onset of adverse events. Furthermore, two principally competing theories on the effect of such small doses are postulated: the threshold model, which assumes that very small exposures are harmless, and the radiation hormesis model, which claims that radiation at very small doses can even be beneficial. The reality for small-dose exposures is still disputed and recent data are probably inconclusive (36). Despite this discussion, a parallel model can be applied to 
ageing, where a high dose response would be comparable to effects seen in the elderly.

The role of mutagens seems to be even more complex. Besides resulting in genetic modifications, they are also very active in the control of epigenetic processes. These include e.g. DNA methylation and acetylation, as well as histone acetylation, influencing the activity of many genes. These are important for the transition from embryonic to fetal stage (37), from youth to old age, from normal tissue to cancerous tissue (38). From this point of view, DNA methylation may be important link between ageing, genome instability and cancerogenesis (39). The role of epigenetics in inactivation of gene repair can be well demonstrated in gastrointestinal tumors, as well as in the case of triple-negative breast cancer. The poor prognosis of a patient is associated with an inactivation of breast cancer 1 (BRCAl) by methylation of its gene promoter $(40,41)$. This gene can participate in DNA repair. Synergism of genetic instability induced by a reduction of activity of gene repair mechanisms with epigenetic mechanisms triggered by e.g. overproduction of reactive oxygen species can be important in cancer initiation and further progression (42). Modern large-scale genomic procedures, in combination with experimental and clinical research, can help us in understanding to this complex interplay.

\section{Genetic Diseases as Models of Ageing and Cancer}

DNA repair is very important for the maintenance of the integrity of an individual genome. It is also a significant aid for the prevention of serious, frequently fatal diseases, including cancer (43). DNA-repair activity seems to be attenuated during the course of ageing. From this point of view, it can be interesting to compare results of ageing with situations seen in diseases or syndromes associated with DNA-repair failure $(44,45)$. Diseases such as xeroderma pigmentosum, Werner syndrome, Lynch syndrome and Fanconi anemia can be considered paradigmatic examples. Association of these rare diseases with untimely occurring malignant tumors was the leading motif in their initial clinical description (30, 46-50).

The Hutchinson-Gilford progeria syndrome is caused by lamin A defect. Affected individuals suffer from premature ageing accompanied by all typical symptoms. Interestingly, patients with this disease also exhibit instability of the genome very similar to physiological ageing (51). Down syndrome induced by chromosome 21 trisomy is also accompanied by premature ageing and genetic instability associated with defective DNA repair $(52,53)$. A high incidence of acute myeloid leukemia in these patients was well documented (54). These data from well-defined genetic diseases suggests that a DNA-repair deficiency in the course of normal ageing can also result in increased risk of cancer in the elderly population (14).

\section{Stroma as a Link Between Wound Healing and Cancer: Controlling Biological Behavior of Tumors}

The capacity for regeneration and wound repair seems to be negatively correlated with longevity from the phylogenetic point of view. On the contrary, cancer incidence is much higher in complex long-living organisms than in simple organisms with a short life expectancy (36). Despite this contrast, there are numerous similarities between the tissue healing/regeneration and cancer. This concept was postulated almost 30 years ago (55). Granulation tissues of wounds and tumor stroma are quite similar. They share similar morphology. Their gene-expression profiles are also remarkably overlapping. Both tissues are composed from activated fibroblasts (producing the extracellular matrix, growth factors and other cytokines and chemokines), inflammatory cells and immature capillaries (56-58). Interestingly, cancer-associated fibroblasts (CAFs) of tumor stroma produce pro-inflammatory cytokines/chemokines such as interleukin 6 (IL6), IL8 and chemokine (C-X-C motif) ligand 1 (CXCL1) (59). Similar products can also be released from specialized inflammatory cells. CAFs are thus important in maintaining the stability of the micromilieu within the tumor. This observation corresponds with the stimulatory role of chronic inflammation on cancer initiation seen in facultative precancerosis. Surprisingly, a secretory phenotype typical for inflammation is also frequently reported during ageing and in cellular senescence (11). Inflammatory cells represent also an important source of reactive oxygen radicals, with the above mentioned consequences (60). The positive effect of stromal cells on cancer progression was documented in many types of tumor, including tumors arising in the squamous stratified epithelium (61). Although the tumor stroma is morphologically not very rich in glioblastoma, it seems to be important for driving the biology even of this type of tumor (62). Moreover, CAFs isolated from other neuroectodermal tumors are able to stimulate invasiveness of glioblastoma cells in vitro (62). Pro-inflammatory cytokines/chemokines such as IL6, IL8 and CXCL1 were also described as having a very important influence on the intercellular crosstalk in other neuroectodermal tumors e.g. in malignant melanoma (63-65). Moreover, IL6, IL8 and CXCL1 were also found to be part of the gene signature of an aggressive malignant glioblastoma typical of old patients (66). In the context of this article, the role of these particular factors is most likely not tumor type-specific because these proteins also participate in intercellular interactions in squamous cell carcinoma. They are also seen in course of wound healing (57) and belong to so called senescence-associated secretory phenotype family (67).

Despite differences in anatomical tumor origin and type, cancer cells are frequently genetically altered and they vitally 
require specific microenvironment support. This seems to be critical for cancer cell proliferation, as well as for the migratory activity of cancer cells and consequently metastasis formation. Stromal dominance can even actively drive cancer progression as in the case of dystrophic epidermolysis bullosa (68). The stroma here becomes very powerful due to chronic inflammation linked to hereditary epidermal fragility. In this case, synergistic cancersupporting microenvironment and life-long inflammation upgrades even relatively non-aggressive cutaneous squamous cell carcinoma to a deadly disease, killing patients.

\section{Paradigms Behind Cancer Biology and Ageing}

Malignant tumors represent by nature a heterogeneous group of diseases. Despite the tumor type and anatomical origin, all tumors can, for the sake of simplicity, be divided into three main categories that can substantiate the final strategy for their prevention and therapy.

The first group is presented by hereditary cancer. Apriori pathological mutation-bearing genetic material is transferred by gametes (for example $B R C A l$ causing breast/ovary cancer or retinoblastoma protein $1(R B 1)$ in retinoblastoma) to offspring. Affected individuals acquire cancer usually in childhood or in early adulthood. Efficient genetic counseling and oncological screening in affected families can be crucially important in order to prevent the clinical manifestation of disease.

Secondly, cancer as an infectious disease is caused by viral infections human papilloma virus and uterine cervix carcinoma, hepatitis virus and hepatocellular carcinoma) or indirectly by bacterial infection (Helicobacter pylori and stomach cancer) or parasitic infestation (in case of chronical bilharsiosis in urinary bladder carcinoma). Vaccine development and an effective nation-wide vaccination campaign along suitable clinical or laboratory screening can prevent of this type of disease.

However, the largest proportion of cancer cases is represented by sporadic tumors. This issue was thoroughly investigated in recent years (54), however, others immediately raised multiple objections against such simplification (69). Despite the ongoing florid discussion, ageing seems to be integral component in both the aforementioned concepts. Due to inherent genetic instability, ageing represents an implicit factor for cancer development. Cancer-affected elderly patients represent an immensely growing target population for cancer therapy in the near future. Limited capacity of DNA repair allowing successful editing of stochastically occurring mutations is further restricted in the elderly by associated epigenetic mechanisms. By extension, a generalized decrease in generepair capacity in the process of ageing might be regarded as an integral regulatory check-point of natural human ontogeny. This mechanism ensures limits of an individual's existence after the accomplishment of individual reproduction and gene spreading (Figure 1) (70).

Factors such as improved hygiene standards, vaccination, efficient anti-infectious therapy, and improvements of interventional and preventive cardiology increase the life expectancy of many individuals, namely in developed countries with good accessibility to high quality medical care. This also leads inevitably to the fact that a substantially large proportion of people break such a set limit of "ontogenetically meaningful survival" living beyond their biological limits. Thus, ageing-associated cancer is a plausible mechanism securely ensuring population exchange.

However, there is a notably growing group of successful cancer-free elderly people such as centenarians. Of course, the overall genetic set-up and individual genetic variants associated with longevity are being intensively studied (71). The question of whether individual extreme long cancer-free survival is the consequence of mutations of putative master genes controlling and coordinating multiple aging-related pathways remains. It is necessary to mention here that these very old cancer-free people also frequently exhibit cancerassociated mutations in their genome but these mutations remain clinically silent (34). Results of these studies are extremely exciting for biologists, but they are naturally opening additional serious ethical as well as existential and philosophical considerations. Is it just a mistake of code which enables an individual to 'escape from the standards' or is there any additional value which might be transferred beyond their individual life?

\section{Cancer and Ageing from a Socioeconomic Point of View}

Longevity, ageing and death are fundamental topics traditionally attracting attention of people across various cultures. Treatises on these aspects of life are frequently a crucial component of many religious and philosophical systems. Ageing represents the factor that predetermines our biological existence with its multiple facets including medical problems such as high cancer incidence. Global rapid increase of the elderly population is frequently refered to as "the grey tsunami". In the scenario of increasing life expectancy worldwide, it is mandatory to identify the characteristics of a healthy aging phenotype. Nevertheless, the associated increased incidence of malignant tumors is also inevitably accompanied by numerous social and economic issues. Oncological care is complicated and psychologically exhausting not only for families, but also for the society as a whole. Modern anticancer therapy is fairly expensive in many cases. Combined data demonstrating the increasing lifespan of population and epidemic-like cancer statistics worldwide should warrant governmental bodies and 
responsible healthcare authorities providing financial budgets necessary to cover the expenses associated with ageingrelated cancer $(72,73)$.

\section{Therapeutic Challenges}

It is estimated that the proportion of people suffering from cancer will increase in the near future. This increase may be associated with serious medical, social and economic problems. These patients will suffer from many ageassociated diseases frequently making them too vulnerable for usual surgery and classical aggressive anticancer therapy. Targeting of the cancer microenvironment can modulate the biological behavior of cancer cells. From this point of view, the therapeutic manipulation of the stroma represents a promising mode of adjuvant therapy. Inactivation of molecules participating in the crosstalk between tumorforming cells seems to be promising therapeutic option. Failure in recruiting stromal elements could potentially be able to repair the low level of differentiation of malignant elements (56). The cancer stroma is strongly infiltrated by specialized inflammatory cells. Many of them significantly stimulate cancer cell proliferation and migration. Moreover, the whole cancer stroma exhibits a similar inflammatory secretory phenotype. Interestingly, well-known simple and inexpensive anti-inflammatory therapy can be useful in cancer treatment as well as in the prevention of the disease $(74,75)$. As an example from an in vitro experiment, acetylsalicylic acid is able to block breast cancer tumorinitiating cells as well as cancer cells by the inhibition of the transforming growth factor $\beta /$ homolog to Drosophila protein, mothers against decapentaplegic protein 4 (TGF $\beta /$ SMAD4) signaling pathway (76). However, the clinical relevancy of this finding must be verified by a carefully designed clinical study. The preventive application of selective anticancer drugs in ageing has also been proposed (77).

\section{Conclusion}

The trend for population ageing will become even more common in many countries worldwide, where it will closely track economic development. The increased incidence of cancer will demand attention of the governmental authorities to establish an adequate economic base necessary for the expensive treatment of numerous patients. This situation also sets a great challenge for the development of breaking innovations for cancer prevention and therapy.

\section{Acknowledgements}

The Authors are grateful to Ivan Helekal for the preparation of Figure 1 and to the following institutions for funding: Ministry of Education, Youth and Sports of CR (project National Sustainability
Program II BIOCEV-FAR, No. LQ1604); Charles University (projects PRVOUK-27, GAUK 44214 and UNCE 204013); Grant Agency of the Czech Republic (grants number P30416-05534S and P304-13-20293S), Ministry of Health of the Czech Republic (grant number P03-15-28933A) and the Slovak Research and Development Agency (grant number APVV-14-0731).

\section{References}

1 ÚZIS: Incidence of malignant neoplasms in the Czech Republic in 2010. Actual Information of Institute of Medical Information of Statistics, ÚZIS, Prague, Czech Republic p. 1-11: 2013.

2 Weir HK, Thompson TD, Soman A, Møller B and Leadbetter S: The past, present, and future of cancer incidence in the United States: 1975 through 2020. Cancer 121: 1827-1837, 2015.

3 ÚZIS: Cancer incidence in the Czech Republic, 2011. ÚZIS ČR, NOR ČR, ÚZIS, Prague, Czech Republic. p.1-263, 2015.

4 Mackenbach: JP: Political conditions and life expectancy in Europe, 1900-2008. Soc Sci Med 82: 134-146, 2013.

5 Mackenbach JP: Convergence and divergence of life expectancy in Europe: a centennial view. Eur J Epidemiol 28: 229-240, 2013.

6 Gunderson K, Wang CY and Wang R: Global prostate cancer incidence and the migration, settlement, and admixture history of the Northern Europeans. Cancer Epidemiol 35: 320-327, 2011.

7 Nyamori JM, Kimani K, Njuguna MW and Dimaras H: The incidence and distribution of retinoblastoma in Kenya. Br J Ophthalmol 96: 141-143, 2012.

8 Korir A, Okerosi N, Ronoh V, Mutuma G and Parkin M: Incidence of cancer in Nairobi, Kenya (2004-2008). Int J Cancer 137: 2053-2059, 2015.

9 Graham A, Adeloye D, Grant L, Theodoratou E and Campbell $\mathrm{H}$ : Estimating the incidence of colorectal cancer in Sub-Saharan Africa: A systematic analysis. J Glob Health 2: 020404: 2012.

10 Rattan SIS: Aging is not a disease: Implications for intervention. Aging Dis 5: 196-202, 2014.

11 Feltes BC, de Faria Poloni J and Bonatto D: The developmental aging and origins of health and disease hypotheses explained by different protein networks. Biogerontol 12: 293-308, 2011.

12 Pitt JN and Kaeberlein M: Why is aging conserved and what can we do about it? PLoS Biol 13: e1002176, 2015.

13 López-Otín C, Blasco MA, Partridge L, Serrano M and Kroemer G: The hallmarks of aging. Cell 153: 1194-1217, 2013.

14 Burkhalter MD, Rudolph KL and Sperka T: Genome instability of ageing stem cells - Induction and defence mechanisms. Ageing Res Rev 23: 29-36, 2015.

15 Yin D and Chen K: The essential mechanisms of aging: Irreparable damage accumulation of biochemical side-reactions. Exp Gerontol 40: 455-465, 2005.

16 Tomasetti C and Vogelstein B: Cancer etiology. Variation in cancer risk among tissues can be explained by the number of stem cell divisions. Science 347: 78-81, 2015.

17 Sell S: Stem cell origin of cancer and differentiation therapy. Crit Rev Oncol Hematol 51: 1-28, 2004.

18 Vahidi Ferdousi L, Rocheteau P, Chayot R, Montagne B, Chaker Z, Flamant P, Tajbakhsh S and Ricchetti M: More efficient repair of DNA double-strand breaks in skeletal muscle stem cells compared to their committed progeny. Stem Cell Res 13: 492$507,2014$. 
19 Løhr M, Jensen A, Eriksen L, Grønbæk M, Loft S and Møller P: Association between age and repair of oxidatively damaged DNA in human peripheral blood mononuclear cells. Mutagenesis 30: 695-700, 2015.

20 MacRae SL, Croken MM, Calder RB, Aliper A, Milholland B, White RR, Zhavoronkov A, Gladyshev VN, Seluanov A, Gorbunova V, Zhang ZD and Vijg J: DNA repair in species with extreme lifespan differences. Aging 7: 1171-1184, 2015.

21 Wang JL, Guo HL, Wang PC and Liu CG: Age-dependent downregulation of DNA polymerase $\delta 1$ in human lymphocytes. Mol Cell Biochem 371: 157-163, 2012.

22 Brun C, Jean-Louis F, Oddos T, Bagot M, Bensussan A and Michel L: Phenotypic and functional changes in dermal primary fibroblasts isolated from intrinsically aged human skin. Exp Dermatol 25: 113-119, 2016.

23 Kalfalah F, Seggewiß S, Walter R, Tigges J, Moreno-Villanueva M, Bürkle A, Ohse S, Busch H, Boerries M, Hildebrandt B, Royer-Pokora B and Boege F: Structural chromosome abnormalities, increased DNA strand breaks and DNA strand break repair deficiency in dermal fibroblasts from old female human donors. Aging 7: 110-122: 2015.

24 Carr LL and Gottschling DE: Does age influence loss of heterozygosity? Exp Gerontol 43: 123-129, 2008.

25 Liu C, Srihari S, Lal S, Gautier B, Simpson PT, Khanna KK, Ragan MA and Lê Cao KA: Personalised pathway analysis reveals association between DNA repair pathway dysregulation and chromosomal instability in sporadic breast cancer. Mol Oncol 10: 179-193, 2016.

26 Bavarva JH, Tae H, McIver L, Karunasena E and Garner HR: The dynamic exome: acquired variants as individuals age. Aging 6: 511-521, 2014

27 Jeppesen DK, Bohr VA and Stevnsner T: DNA repair deficiency in neurodegeneration. Prog Neurobiol 94: 166-200, 2011.

28 Canugovi C, Misiak M, Ferrarelli LK, Croteau DL and Bohr VA: The role of DNA repair in brain related disease pathology. DNA Repair 12: 578-587, 2013.

29 Behrens A, van Deursen JM, Rudolph KL and Schumacher B: Impact of genomic damage and on stem cell function. Nat Cell Biol 16: 201-207, 2014.

30 Haraldsdottir S, Hampel H, Tomsic J, Frankel WL, Pearlman R, de la Chapelle A and Pritchard CC: Colon and endometrial cancers with mismatch repair deficiency can arise from somatic, rather than germline, mutations. Gastroenterology 147: 13081316,2014

31 Inomata $\mathrm{K}$, Aoto $\mathrm{T}$, Binh NT, Okamoto N, Tanimura S, Wakayama T, Iseki S, Hara E, Masunaga T, Shimizu H and Nishimura EK: Genotoxic stress abrogates renewal of melanocyte stem cells by triggering their differentiation. Cell 137: 1088-1099, 2009.

32 Alexandrov LB, Nik-Zainal S, Wedge DC et al: Signatures of mutational processes in human cancer. Nature 500: 415-421, 2013.

33 Watson IR, Takahashi K, Futreal PA and Chin L: Emerging patterns of somatic mutations in cancer. Nat Rev Genet 14: 703718,2013

34 McKerrell T, Park N, Moreno T, Grove CS, Ponstingl H, Stephens J, Understanding Society Scientific Group, Crawley C, Craig J, Scott MA, Hodkinson C, Baxter J, Rad R, Forsyth DR, Quail MA, Zeggini E, Ouwehand W, Varela I and Vassiliou GS: Leukemia-associated somatic mutations drive distinct patterns of age-related clonal hemopoiesis. Cell Rep 10: 1239-1245, 2015.
35 Greaves M: Evolutionary determinants of cancer. Cancer Discov 5: 806-820, 2015.

36 Smetana K Jr., Dvořánková B and Lacina L: Phylogeny, regeneration, ageing and cancer: role of microenvironment and possibility of its therapeutic manipulation. Folia Biol (Praha) 59: 207-216, 2013.

37 Leseva M, Knowles BB, Messerschmidt DM and Solter D: Erase-Maintain-Establish: Natural Reprogramming of the Mammalian Epigenome. Cold Spring Harb Symp Quant Biol 80: 155-163, 2015.

38 Afanas'ev I: Mechanisms of superoxide signaling in epigenetic processes: relation to aging and cancer. Aging Dis 6: 216-227, 2015.

39 Meng H, Cao Y, Qin J, Song X, Zhang Q, Shi Y and Cao L: DNA methylation, its mediators and genome integrity. Int J Biol Sci 11: 604-617, 2015.

40 Bernstein $\mathrm{C}$ and Bernstein $\mathrm{H}$ : Epigenetic reduction of DNA repair in progression to gastrointestinal cancer. World $\mathrm{J}$ Gastrointest Oncol 7: 30-46, 2015.

41 Yamashita N, Tokunaga E, Kitao H, Hitchins M, Inoue Y, Tanaka K, Hisamatsu Y, Taketani K, Akiyoshi S, Okada S, Oda Y, Saeki H, Oki E and Maehara Y: Epigenetic inactivation of BRCA1 through promoter hypermethylation and its clinical importance in triple-negative breast cancer. Clin Breast Cancer 15: 498-504, 2015.

42 Santos JC and Ribeiro ML: Epigenetic regulation of DNA repair machinery in Helicobacter pylori-induced gastric carcinogenesis. World J Gastroenterol 21: 9021-9037, 2015.

43 Moraes MC, Neto JB and Menck CF: DNA repair mechanisms protect our genome from carcinogenesis. Front Biosci (Landmark Ed) 17: 1362-1388, 2012.

44 Suhasini AN and Brosh RM Jr.: DNA helicases associated with genetic instability, cancer, and aging. Adv Exp Med Biol 767: 123-144, 2013.

45 Edifizi D and Schumacher B: Genome instability in development and aging: insights from nucleotide excision repair in humans, mice, and worms. Biomolecules 5: 1855-1869, 2015.

46 Cleaver JE: Common pathways for ultraviolet skin carcinogenesis in the repair and replication defective groups of xeroderma pigmentosum. J Dermatol Sci 23: 1-11, 2000.

47 Knoch J, Kamenisch Y, Kubisch C and Berneburg M: Rare hereditary diseases with defects in DNA-repair. Eur J Dermatol 22: 443-455, 2012.

48 Romick-Rosendale LE, Lui VW, Grandis Jr. and Wells SI: The Fanconi anemia pathway: repairing the link between DNA damage and squamous cell carcinoma. Mutat Res 743-744: 78$88,2013$.

49 Menck CF and Munford V: DNA repair diseases: What do they tell us about cancer and aging? Genet Mol Biol 37(1 Suppl): 220-233, 2014.

50 Oshima J, Sidorova JM and Monnat RJ Jr.: Werner syndrome: Clinical features, pathogenesis and potential therapeutic interventions. Ageing Res Rev. pii: S1568-1637(16)30026-5. doi: 10.1016/j.arr.2016.03.002, 2016.

51 Gonzalo S and Kreienkamp R: DNA repair defects and genome instability in Hutchinson-Gilford Progeria Syndrome. Curr Opin Cell Biol 34: 75-83, 2015.

52 Patterson D and Cabelof DC: Down syndrome as a model of DNA polymerase beta haploinsufficiency and accelerated aging. Mech Ageing Dev 133: 133-137, 2012. 
53 Necchi D, Pinto A, Tillhon M, Dutto I, Serafini MM, Lanni C, Govoni S, Racchi M and Prosperi E: Defective DNA repair and increased chromatin binding of DNA repair factors in Down syndrome fibroblasts. Mutat Res 780: 15-23, 2015.

54 Xavier AC, Ge Y and Taub JW: Down syndrome and malignancies: a unique clinical relationship: a paper from the 2008 William Beaumont hospital symposium on molecular pathology. J Mol Diagn 11: 371-380, 2009.

55 Dvorak H: Tumors: The wounds that do not heal. New Engl J Med 315: 1650-1659, 1986.

56 Smetana K Jr., Dvořánková B, Lacina L, Strnad H, Kolář M, Chovanec M, Plzák J, Čada Z, Vlček Č, Szabo P, Betka J, Motlík J, Kovářová $\mathrm{H}$ and Jarkovská K: Combination of antibodies or their Fab fragments for use as drugs and pharmaceutic tools containing these antibodies and fragments. Czech Patent No. 303227, 2012.

57 Smetana K Jr., Szabo P, Gal P, André S, Gabius H-J, Kodet O and Dvořánková B: Emerging role of tissue lectins as microenvironmental effectors in tumors and wounds. Histol Histopathol 30: 293-309, 2015.

58 Delinasios JG, Angeli F, Koumakis G, Kumar S, Kang WH, Sica G, Iacopino F, Lama G, Lamprecht S, Sigal-Batikoff I, Tsangaris GT, Farfarelos CD, Farfarelos MC, Vairaktaris E, Vassiliou S, Delinasios GJ: Proliferating fibroblasts and HeLa cells cocultured in vitro reciprocally influence growth patterns, protein expression, chromatin features and cell survival. Anticancer Res 35: 1881-1916, 2015

59 Kolář M, Szabo P, Dvořánková B, Lacina L, Gabius H-J, Strnad H, Sáchová J, Vlček C, Plzák J, Chovanec M, Cada Z, Betka J, Fík Z, Pačes J, Kovářová H, Motlík J, Jarkovská K and Smetana $\mathrm{K}$ Jr.: Upregulation of IL-6, IL-8 and CXCL-1 production in dermal fibroblasts by normal/malignant epithelial cells in vitro: Immunohistochemical and transcriptomic analyses. Biol Cell 104: 738-751, 2012.

60 Halliwell B: Oxidative stress and cancer: have we moved forward? Biochem J 401: 1-11, 2007.

61 Plzák J, Lacina L, Chovanec M, Dvoránková B, Szabo P, Cada $\mathrm{Z}$ and Smetana $\mathrm{K}$ Jr.: Epithelial-stromal interaction in squamous cell epithelium-derived tumors: an important new player in the control of tumor biological properties. Anticancer Res 30: 455462,2010

62 Trylcova J, Busek P, Smetana K Jr., Balaziova E, Dvorankova B, Mifkova A and Sedo A: Effect of cancer-associated fibroblasts on the migration of glioma cells in vitro. Tumour Biol 36: 5873-5879, 2015.

63 Sayegh ET, Kaur G. Bloch O and Parsa AT: Systematic review of protein biomarkers of invasive behavior in glioblastoma. Mol Neurobiol 49: 1212-1244, 2014.

64 Kodet O, Lacina L, Krejčí E, Dvořánková B, Grim M, Štork J, Kodetová D, Vlček Č, Šáchová J, Kolář M, Strnad H and Smetana K Jr.: Melanoma cells influence the differentiation pattern of human epidermal keratinocytes. Mol Cancer 14: 1, 2015 .
65 Jobe NP, Rösel D, Dvořánková B, Kodet O, Lacina L, Mateu R, Smetana K Jr., and Brábek J: Simultaneous blocking of IL-6 and IL-8 is sufficient to fully inhibit CAF-induced human melanoma cell invasiveness. Histochem. Cell Biol 146: 205-217, 2016.

66 Coppola D, Balducci L, Chen DT, Loboda A, Nebozhyn M, Staller A, Fulp WJ, Dalton W, Yeatman T and Brem S: Senescence-associated-gene signature identifies genes linked to age, prognosis, and progression of human gliomas. J Geriatr Oncol 5: 389-399, 2014.

67 Coppé JP, Desprez PY, Krtolica A and Campisi J: The senescence-associated secretory phenotype: the dark side of tumor suppression. Annu Rev Pathol 5: 99-118, 2010.

$68 \mathrm{Ng}$ YZ, Pourreyron C, Salas-Alanis JC, Dayal JH, CepedaValdes R, Yan W, Wright S, Chen M, Fine JD, Hogg FJ, McGrath JA, Murrell DF, Leigh IM, Lane EB and South AP:Fibroblast-derived dermal matrix drives development of aggressive cutaneous squamous cell carcinoma in patients with recessive dystrophic epidermolysis bullosa. Cancer Res 72: 3522-3534, 2012.

$69 \mathrm{Wu} \mathrm{S}$, Powers S, Zhu W and Hannun YA: Substantial contribution of extrinsic risk factors to cancer development. Nature 529: 43-47, 2016.

70 Carnes BA and Witten TM: How long must humans live? J Gerontol A Biol Sci Med Sci 69: 965-970, 2014.

71 Gems D and McElwee JJ: Ageing: Microarraying mortality. Nature 424: 259-261, 2003.

72 Global Burden of Disease Cancer Collaboration: The Global Burden of Cancer 2013. JAMA Oncol 1: 505-527, 2015.

73 Shih YC, Hurria A.: Preparing for an epidemic: cancer care in an aging population. Am Soc Clin Oncol Educ Book 2014: 133137, 2014

74 Benamouzig R, Uzzan B, Little J and Chaussade S: Low dose aspirin, COX-inhibition and chemoprevention of colorectal cancer. Curr Top Med Chem 5: 493-503, 2005.

75 Famenini S, Duan L and Young L: Aspirin use and melanoma: A UCLA pilot study. J Am Acad Dermatol 72: 1094-1095, 2015.

76 Maity G, De A, Das A, Banerjee S, Sarkar S and Banerjee SK: Aspirin blocks growth of breast tumor cells and tumor-initiating cells and induces reprogramming factors of mesenchymal to epithelial transition. Lab Invest 95: 702-717, 2015.

77 Blagosklonny MV: Selective anti-cancer agents as anti-aging drugs. Cancer Biol Ther 14: 1092-1097, 2013.

Received August 2, 2016

Revised September 5, 2016 Accepted September 12, 2016 